\title{
Screening for Subclinical Ketosis in Dairy Cattle by Fourier Transform Infrared Spectrometry
}

\author{
A. P. W. de Roos, ${ }^{\star 1}$ H. J. C. M. van den Bijgaart, † J. Hørlyk, $\ddagger$ and G. de Jong ${ }^{\star}$ \\ *NRS, PO Box 454, 6800 AL Arnhem, the Netherlands \\ †Netherlands Milk Control Station (MCS), PO Box 119, 7200 AC Zutphen, the Netherlands \\ $\ddagger$ Foss Analytical A/S, PO Box 260, DK-3400 Hillerød, Denmark
}

\section{ABSTRACT}

Subclinical ketosis is a metabolic disorder in highproducing dairy cattle that can be detected by ketone bodies in milk: acetone (Ac), acetoacetate (AcAc), and $\beta$-hydroxybutyrate (BHBA). Fourier transform infrared (FTIR) spectrometry is to a growing extent used for determination of milk constituents in milk recording, but as yet there is no calibration for ketone bodies available. The objective of this study was therefore to build a calibration for the MilkoScan FT6000 (FOSS Analytical A/S, Hillerød, Denmark) for Ac, AcAc, and BHBA and to evaluate the FTIR predictions for detection of subclinical ketosis. From 217 herds, 1,080 milk samples were taken from fresh multiparous dairy cows. The Ac, AcAc, and BHBA concentrations were determined by chemical methods using segmented flow analysis. Because of its low concentration, AcAc seemed to be hardly detectable and was therefore not considered further. The correlation between the chemical method results of Ac and BHBA was 0.82, indicating that both ketone bodies were elevated in milk during subclinical ketosis. In wk 1 postpartum, however, most samples with a high Ac concentration did not have a high BHBA concentration, whereas after wk 5 postpartum most samples with a high BHBA concentration did not have a high Ac concentration. For Ac and BHBA, the correlation coefficients between the FTIR predictions and the chemical results were around 0.80 with standard error of cross validation values of 0.184 and $0.064 \mathrm{mM}$ for Ac and BHBA, respectively. Using thresholds of $0.15 \mathrm{mM}$ for Ac and $0.10 \mathrm{~m} M$ for BHBA, high values for Ac or BHBA were detected with a sensitivity of 69 to $70 \%$, a specificity of $95 \%$, with 25 to $27 \%$ false positives and 6 to $7 \%$ false negatives. It is argued that FTIR predictions for Ac and BHBA are valuable for screening cows on subclinical ketosis, especially when used in combination with other indicators, and can serve in the evalua-

Received April 6, 2006.

Accepted December 18, 2006.

${ }^{1}$ Corresponding author: roos.s@nrs.nl tion of the herd health status with respect to subclinical ketosis.

Key words: ketosis, infrared spectrometry, milk

\section{INTRODUCTION}

Clinical ketosis is a metabolic disorder in high-producing dairy cattle that occurs typically in the first 2 mo after calving with a prevalence of around 5\% (Lyons et al., 1991; Uribe et al., 1995). Subclinical ketosis is defined as blood serum BHBA above a threshold (e.g., $1,200 \mu \mathrm{mol} / \mathrm{L}$ ) and has a prevalence of around 15 to 30\% (Dohoo and Martin, 1984; Duffield et al., 1998; Geishauser et al., 1998; Enjalbert et al., 2001). Ketosis is caused by a severe negative energy balance, because of high milk production and insufficient energy intake, and excessive body fat mobilization. The reasons for insufficient energy intake may be poor ration quality, insufficient food intake, or other diseases (e.g., milk fever). Ketosis is associated with a loss in milk production and a greater incidence of left-displaced abomasum, metritis, cystic ovaries, resumption of postpartum luteal function, and mastitis (Dohoo and Martin, 1984; Correa et al., 1993; Reksen et al., 2002).

Clinical and subclinical ketosis result in elevated concentrations of ketone bodies [acetone (Ac), acetoacetate (AcAc), and BHBA] in blood and milk. Enjalbert et al. (2001) have shown that ketone body concentrations in blood and milk correlate well $(r=0.66$ to 0.96$)$, and from a practical point of view, detection of subclinical ketosis is much easier in milk than in blood. Therefore, several ketone tests are available to test cows for subclinical ketosis based on milk samples, with varying sensitivity and specificity (Geishauser et al., 1998).

Hansen (1999) and Heuer et al. (2001) have presented a method for screening cows on subclinical ketosis by determining milk Ac concentration with Fourier transform infrared (FTIR) spectrometry. The FTIR spectrometry is fast and inexpensive and therefore easy to implement on a large scale. The accuracy of Ac measurements was sufficient to classify cows into healthy and possibly ketotic and to present a herd parameter for 
the prevalence of subclinical ketosis. Methods for determination of milk BHBA or AcAc with FTIR spectrometry have not been presented yet.

Subclinical ketosis has been associated with increased fat and urea concentrations and decreased protein and lactose concentrations in milk (Miettinen, 1994; Reist et al., 2002). Duffield (2003) predicted subclinical ketosis from fat to protein ratio and with sensitivity 58\% and specificity $69 \%$. Milk recording herd reports in the Netherlands therefore present the percentage of fresh cows that have a difference between fat and protein concentration of more than 1.25 percentage units. This parameter is influenced by other factors as well, so it may not be very reliable as an indicator for subclinical ketosis. Additional information on ketone bodies may therefore improve this reliability and provide more support to the farmer to monitor and prevent subclinical ketosis in his herd.

The purpose of this study was to build a calibration for the MilkoScan FT6000 (Foss Analytical A/S, Hillerød, Denmark) for Ac, AcAc, and BHBA and to evaluate the FTIR predictions for the detection of subclinical ketosis.

\section{MATERIALS AND METHODS}

\section{Collection of Milk Samples}

Milk samples were collected via regular milk recording in 217 herds in the Netherlands in March and April 2005. The herds were selected for breed composition ( $>85 \%$ Holstein-Friesian), annual milk production per cow $(>8,000 \mathrm{~kg})$, and proportion of cows within 60 d postpartum with fat $\%$ - protein $\%>1.25(>15 \%)$. Farmers were asked to select the 5 cows that had calved most recently, excluding heifers, and take one extra sample (morning or evening) per cow, besides the samples that were taken for the regular milk recording. The samples were collected in $100-\mathrm{mL}$ vials with a cap and preserved with $0.03 \%$ (by mass) sodium azide. In total, 1,080 samples were taken and transported within 1 to $5 \mathrm{~d}$ to the MCS laboratory for analysis. The percentages of samples from cows in lactation wk $0(=\mathrm{d} 0$ to 6 after calving), $1,2,3,4,5,6,7,8,9$ and $>9$ were 4 , $15,14,13,11,9,9,7,4,3$, and $11 \%$, respectively.

\section{Chemical Methods}

Chemical analyses were executed with segmented flow methods, applying $\mathrm{SAN}^{++}$equipment (Skalar, Breda, the Netherlands). Acetone was determined through separation from the sample by gas diffusion through a Teflon membrane. The subsequent reaction with hydroxylamine resulted in a $\mathrm{pH}$ shift, which was measured photometrically at $520 \mathrm{~nm}$ using methyl or- ange as an indicator (Skalar method, catalog number 110-363). Executed validation studies revealed a limit of detection of $0.06 \mathrm{mmol} / \mathrm{L}$ and a repeatability $\mathrm{r}$ of $0.06 \mathrm{mmol} / \mathrm{L}$ in the range up to $1.5 \mathrm{mmol} / \mathrm{L}$. For the measurement of AcAc, the sample was preheated by placing a sealed container in a water bath at $100^{\circ} \mathrm{C}$ during $35 \mathrm{~min}$. After mixing, the total amount of Ac and AcAc was determined according to the described procedure for the determination of Ac. The difference between the 2 values corresponded to the AcAc concentration. The BHBA was determined by dialyzing a buffered milk sample against a Tris buffer solution $(\mathrm{pH}=$ 9 ). In the presence of 3-hydroxybutyrate dehydrogenase, BHBA was oxidized by NAD to AcAc and NADH. The amount of NADH was measured photometrically at $340 \mathrm{~nm}$ (Skalar method, catalog number 388-301). The limit of detection was $0.04 \mathrm{mmol} / \mathrm{L}$, whereas for the repeatability a value of $0.03 \mathrm{mmol} / \mathrm{L}$ was obtained in the range up to $0.6 \mathrm{mmol} / \mathrm{L}$. Adding BHBA stock solutions to milk samples showed a recovery of $110 \%$. It is noted that reported results in test samples have not been corrected for the observed recovery.

The applied preservative in the test samples was shown to have no significant influence on the measured concentrations of ketone bodies.

\section{Infrared Spectrometry Method}

Collected samples were gently preheated to $40^{\circ} \mathrm{C}$ and mixed before analysis with a MilkoScan FT6000 (Foss Analytical A/S). This FTIR instrument was used according to the instructions of the manufacturer with operational calibrations for (reference methods in brackets) fat (ISO 1211; IDF 1), protein (ISO 8968; IDF 20-1), lactose (HPLC method), and urea (ISO 14637; IDF 195). Resulting spectra were recorded in data files for further processing.

\section{Development of the Calibration}

For the development of the calibration, Matlab 7.0.0 (The MathWorks Inc., Natick, MA) was used with Fossdeveloped algorithms. The basic data were provided in 30 different data sets with a total of 2,165 spectra (originating from 1,080 samples). Data were analyzed with respect to Ac (2,111 spectra), AcAc (1,174 spectra), and BHBA (2,123 spectra).

Different combinations of spectral ranges were tested to obtain optimal results. Calibrations models for Ac, AcAc, and BHBA were developed using both normal and log-transformed data, no variable selection method, and the very simple principal variables. The choice of variable selection methods was based on the fact that different variable selection methods do not result in 
Table 1. Descriptive statistics of chemical method results for acetone, BHBA, and acetoacetate $(\mathrm{m} M)$

\begin{tabular}{lrrr}
\hline Item & Acetone & BHBA & Acetoacetate \\
\hline No. of samples & 1,063 & 1,069 & \multicolumn{1}{c}{1,045} \\
Average & 0.146 & 0.078 & 0.010 \\
Minimum & -0.021 & -0.020 & -0.051 \\
50th percentile & 0.059 & 0.042 & 0.004 \\
75th percentile & 0.106 & 0.080 & 0.023 \\
90th percentile & 0.290 & 0.180 & 0.047 \\
95th percentile & 0.580 & 0.276 & 0.068 \\
Maximum & 3.960 & 0.838 & 0.240 \\
\hline
\end{tabular}

drastically different calibration models. With the log10transformed Ac values, a few samples with Ac results above $1 \mathrm{~m} M$ were removed as outliers.

\section{RESULTS AND DISCUSSION}

\section{Chemical Method Results}

Table 1 shows the results of the chemical analysis for Ac, AcAc, and BHBA. For AcAc, $41.8 \%$ of the chemical method results was negative, probably because of its low concentration and the fact that a differential method was applied. It was concluded that the applied chemical method was not suitable for an adequate quantitative determination of AcAc. Therefore, AcAc is not considered further in this paper. For Ac and BHBA only 1.0 and $0.4 \%$ of the chemical method results were negative, respectively. The average Ac and BHBA concentrations were 0.146 and $0.078 \mathrm{~m} M$, respectively, and the distribution of Ac and BHBA measurements was clearly skewed. The 90th percentiles for Ac and BHBA were 0.290 and $0.180 \mathrm{mM}$, respectively. These values were consistent with most other literature; for example, Enjalbert et al. (2001) and Larsen and Nielsen (2005). Figure 1 shows the relationship between the chemical method results for Ac and BHBA. The correlation between Ac and BHBA was 0.82, whereas Enjalbert et al. (2001) found a correlation of 0.68 .

Cows with Ac $<0.106 \mathrm{mM}$ (lowest $75 \%$ ) produced on average $39.9 \mathrm{~kg}$ of milk with $4.49 \%$ fat, $3.30 \%$ protein, $4.64 \%$ lactose, $22.4 \mathrm{mg} / 100 \mathrm{~g}$ of urea, and $197,000 \mathrm{so}-$ matic cells per $\mathrm{mL}$, whereas cows with Ac $>0.580 \mathrm{mM}$ (highest $5 \%$ ) produced on average $36.6 \mathrm{~kg}$ of milk with $5.90 \%$ fat, $3.17 \%$ protein, $4.44 \%$ lactose, $18.0 \mathrm{mg} / 100 \mathrm{~g}$ of urea, and 238,000 somatic cells per mL. Except for urea, this corresponds well to Miettinen (1994), who reported that, before clinical ketosis, milk Ac was negatively correlated with milk yield, protein percentage, and lactose percentage, whereas it was positively correlated with fat percentage and urea concentration.

The percentage of samples with Ac $>0.290 \mathrm{mM}$ (highest $10 \%$ ) was less than $4 \%$ for cows in parity 2 , whereas it ranged from 9 to $19 \%$ for parity $3,4,5$, and $6+$. Similar results were found for BHBA. Figure 2 gives the percentage of samples with Ac $>0.290 \mathrm{~m} M$ or BHBA $>0.180 \mathrm{~m} M$ (highest 10\%) per week of lactation. It shows the highest percentage is found in wk 1 for Ac and in wk 3 for BHBA. In wk 1 there were many samples with high Ac, but normal BHBA, whereas in wk 6 there were relatively many samples with high BHBA but normal Ac. Duffield et al. (1998) showed that the percentage of cows with high blood BHBA was highest in wk 2 and much smaller in or after wk 6 . Reist et al. (2003) found that there was a time lag of 1 to $3 \mathrm{wk}$ between energy balance and blood glucose nadir and NEFA peak on one hand and maximal blood BHBA concentrations on the other hand.

\section{Infrared Measurement Results}

The nontransformed Ac data lead to calibration models, which gave $R^{2}$ ranges from 0.10 to 0.37 and therefore were not used. The logarithmic transformation of the Ac values did increase the $R^{2}$, ranging from 0.18 for the simplest model and up to 0.72 for the most complex model. The standard error of cross validation (SECV) for the transformed Ac values amounted to $0.184 \mathrm{~m} M$, whereas Hansen (1999) reported an $\mathrm{R}^{2}$ of 0.81 and a root mean square error of prediction of 0.27 $\mathrm{m} M$ for measuring Ac with a MilkoScan FT 120. The root mean square error of prediction can be compared directly with SECV, although it is computed in a slightly different manner. For the nontransformed BHBA data, $\mathrm{R}^{2}$ in the resulting calibration models ranged from 0.10 to 0.64 , whereas for log-transformed data $R^{2}$ values from 0.09 to 0.63 were obtained. With SECV values down to $0.065 \mathrm{mM}$ (instead of $0.075 \mathrm{mM}$ for the nontransformed data) the log-transformed data seemed to provide the best basis.

Figures 3 and 4 show the relationship between the chemical method results and the prediction by FTIR spectrometry for Ac and BHBA, respectively. The correlation between the chemical method results and the prediction was 0.85 for Ac and 0.79 for BHBA.

\section{Screening for Subclinical Ketosis}

The correlation between chemical method results and predicted concentrations may not be very high as compared with calibrations for the main constituents in milk; however, it does provide valuable information for the screening on subclinical ketosis. For example, with a chosen threshold for Ac $=0.15 \mathrm{~m} M$, the number of samples that was high/high by the chemical method and the prediction, respectively, was 249 , whereas high/ low was 107 , low/high was 92 , and low/low was 1,632 . 


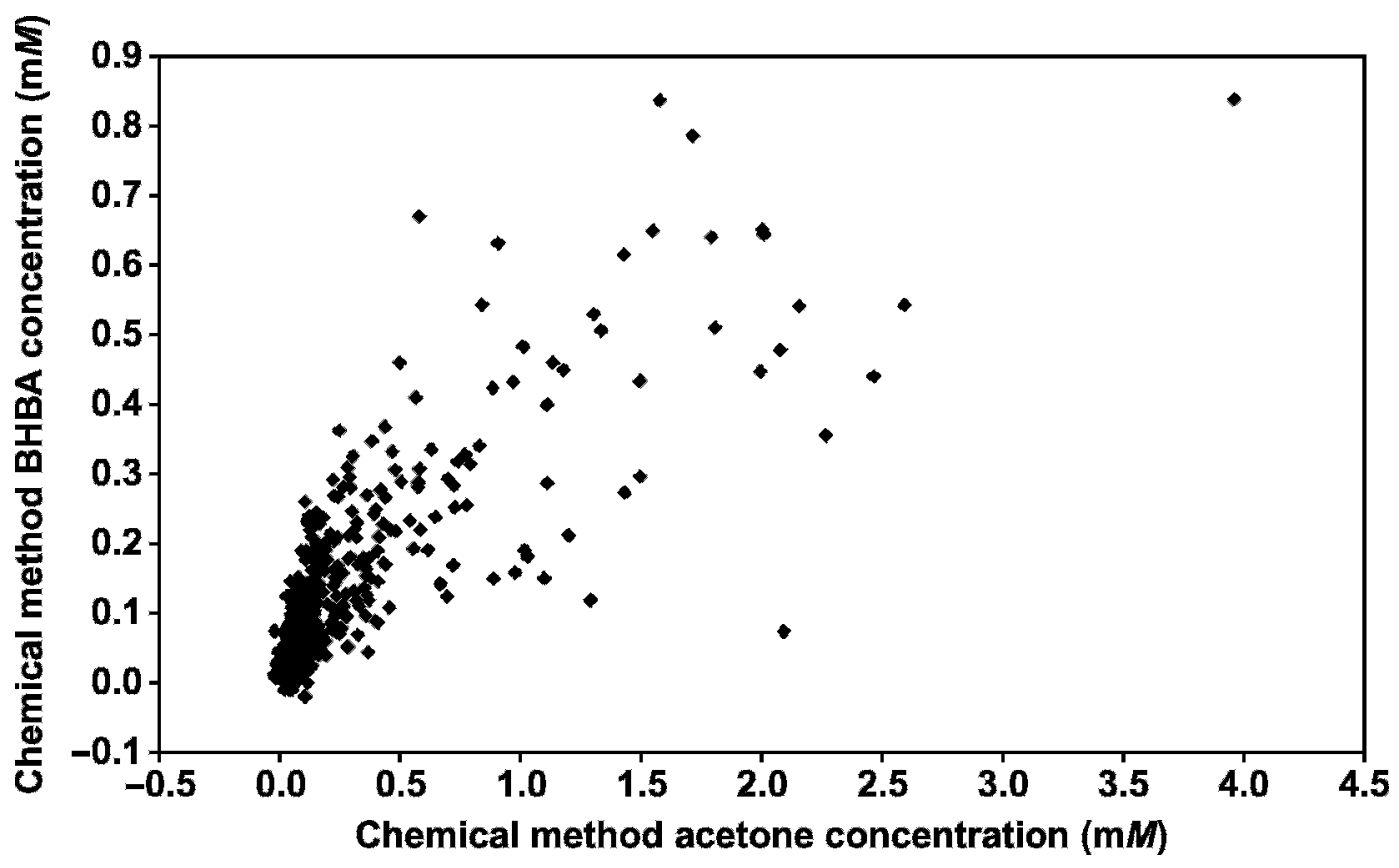

Figure 1. Relationship between the chemical method results for acetone and BHBA.

Note that the total number is 2,080, which originated from 2,111 spectra for Ac, coming from 1,080 milk samples. From this, a sensitivity of $249 /(249+107)=70 \%$ and a specificity of $1,632 /(92+1,632)=95 \%$ can be calculated. Furthermore, the positive predictive value was $249 /(249+92)=73 \%$, and the negative predictive value was $1,632 /(107+1,632)=94 \%$. Similarly, with a threshold for BHBA $=0.10 \mathrm{mM}$, the sensitivity was $69 \%$, specificity was $95 \%$, positive predictive value was $75 \%$, and negative predictive value was $93 \%$. Enjalbert et al. (2001) proposed thresholds for milk Ac and BHBA of 0.16 and $0.07 \mathrm{mM}$, respectively.

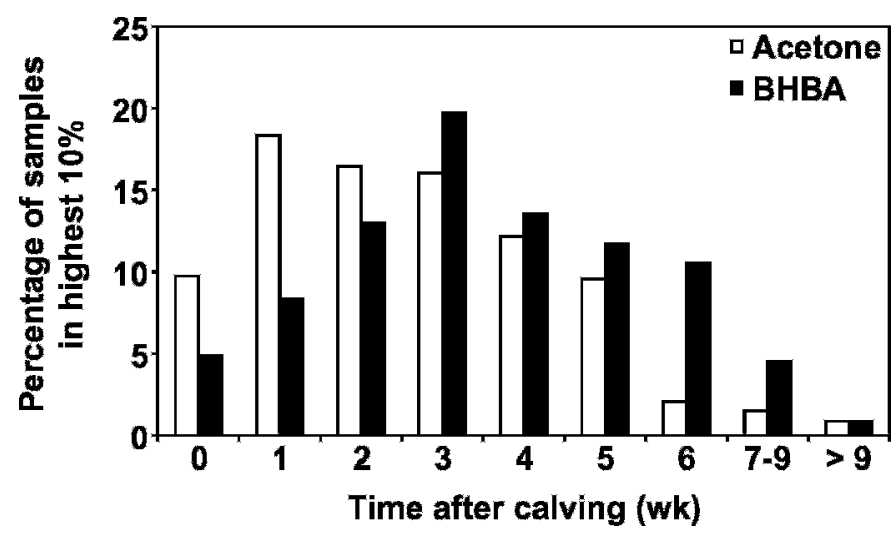

Figure 2. Percentage of samples in highest $10 \%$ for acetone $(>0.290$ $\mathrm{m} M)$ and BHBA $(>0.180 \mathrm{~m} M)$ according to week after calving.
Geishauser et al. (1998) compared several cowside tests to detect subclinical ketosis from milk samples and found sensitivities between 5 and $72 \%$ and specificities between 89 and 100\% (excluding one test with specificity $55 \%$ ). Similar values were reported by Geishauser et al. (2000) and Carrier et al. (2004), who also looked at a cowside test based on urine samples. Compared with these cowside tests, the sensitivity and specificity values found in this study were very similar, although it should be noted that in this study cows were not diagnosed for subclinical ketosis by measuring blood BHBA. Screening cows for subclinical ketosis through FTIR spectrometry after a regular milk recording has several advantages, however (e.g., it is much cheaper, requires no extra labor from the farmer, all recorded cows are measured at each herd test, and the data are automatically stored in a database, which is advantageous for monitoring the herd management).

With milk recording, all samples may be tested for Ac and BHBA by FTIR spectrometry, simultaneously with the prediction of the other milk constituents. The milk recording organization may list the cows with Ac or BHBA above a certain threshold, so the farmer knows which cows potentially have subclinical ketosis. As described above, some of the cows will be falsely identified as ketotic, so additional information about the cow is needed to determine whether she is truly in subclinical ketosis. This can partly be provided for by the milk recording organization by evaluating the lactation 


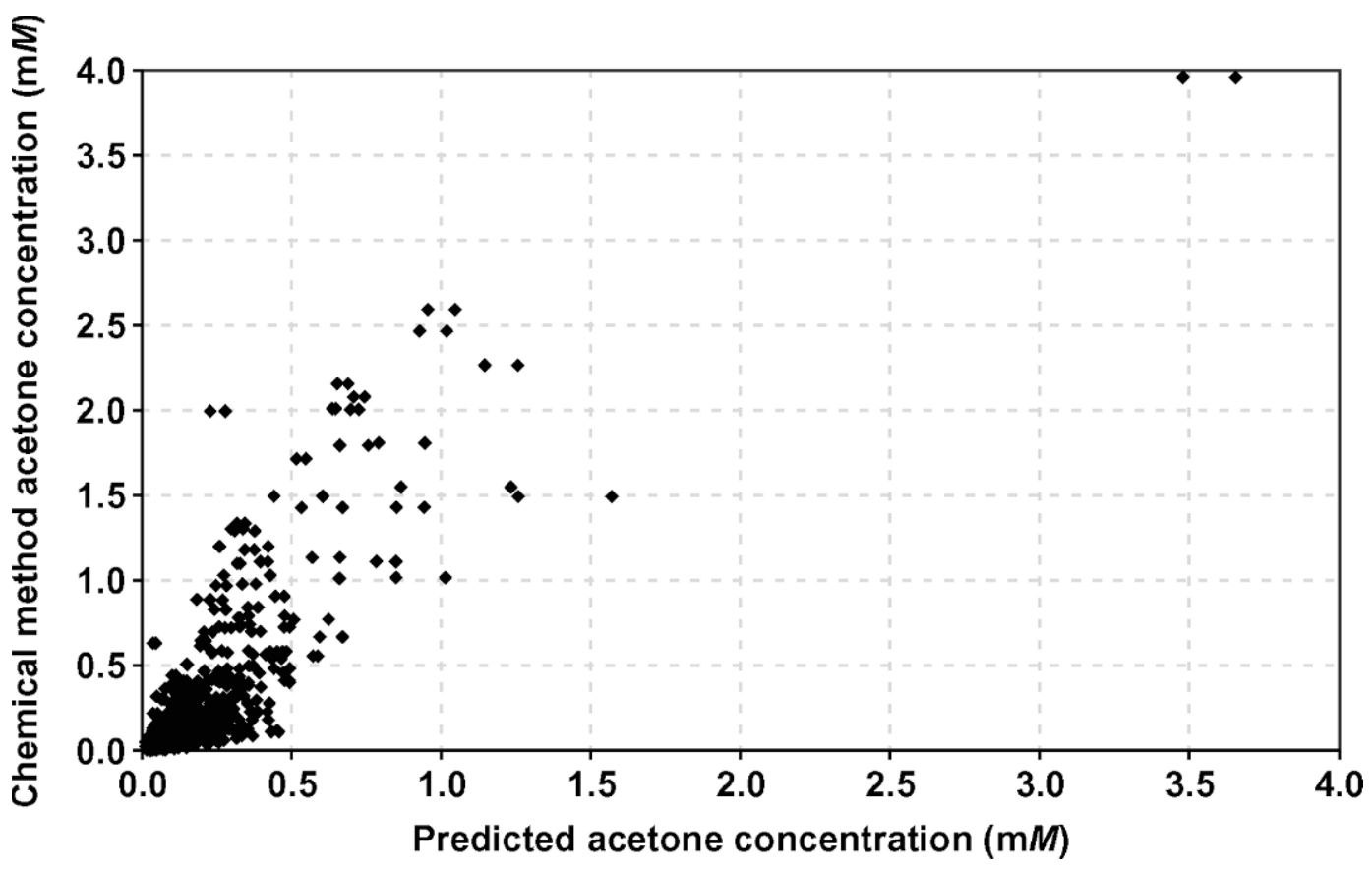

Figure 3. Relationship between the chemical method concentration and the concentration predicted by FTIR spectrometry for acetone $(\mathrm{n}=2,080)$.

stage of the cow, the milk production, and the concentrations of fat, protein, and maybe also lactose (Miettinen, 1994; Reist et al., 2002). Using the FTIR predic- tions of Ac and BHBA and the other information, the milk recording organization or a research institute can develop risk estimators for subclinical ketosis. The

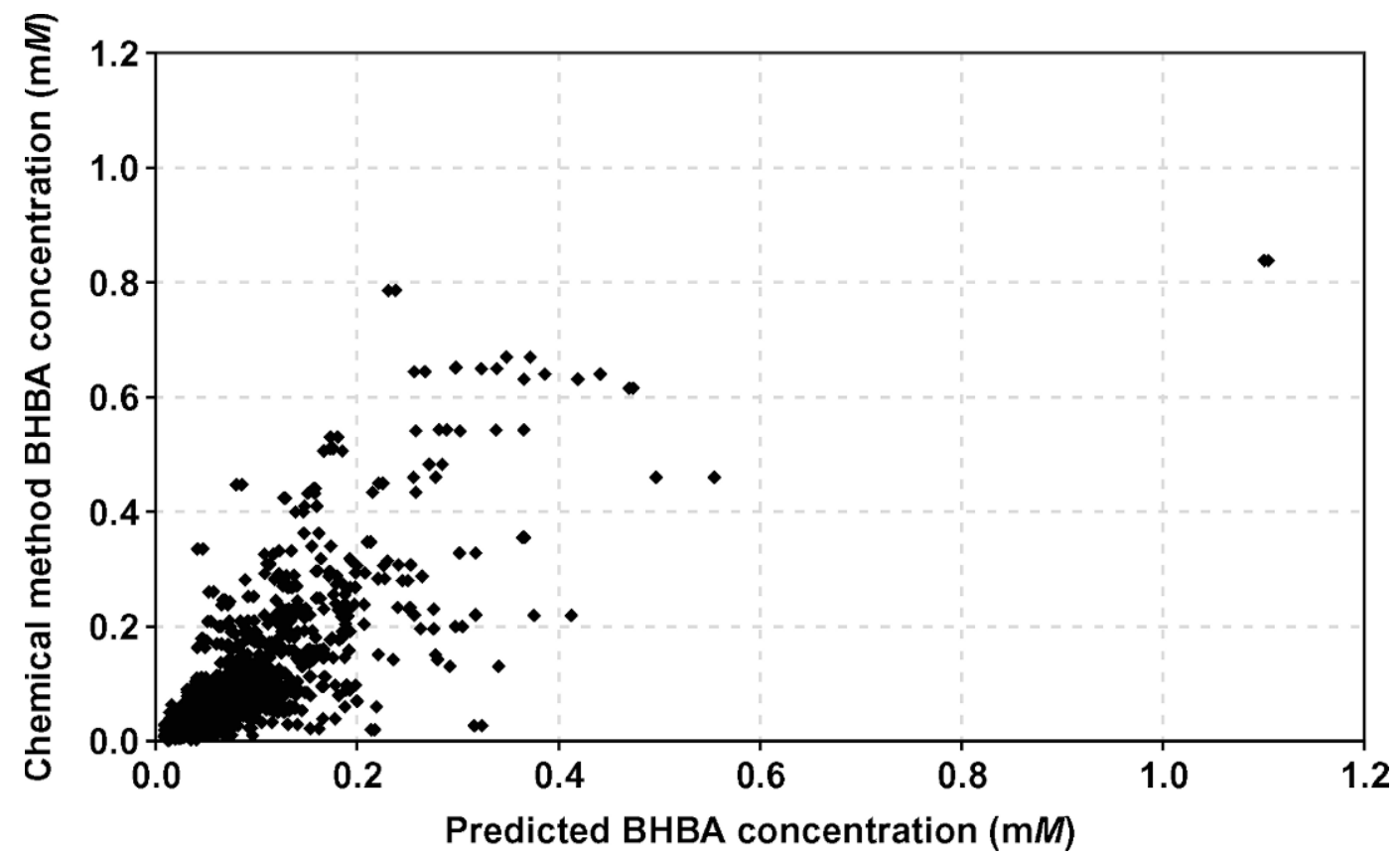

Figure 4. Relationship between the chemical method concentration and the concentration predicted by FTIR spectrometry for BHBA ( $\mathrm{n}=2,094$ ). 
highest estimates will then be obtained for cows with high values for Ac and BHBA, that are in wk 1 to 6 of lactation, have a high expected milk production, but with a fat concentration that is above expectation and a protein and lactose concentration that is below expectation. The expected milk production and composition can be derived from modeling the effects of parity, lactation stage, season etc., and possibly also the effects of the herd and the individual cow.

On a herd level, the percentage of cows detected as subclinically ketotic can be used as a herd evaluation parameter for subclinical ketosis, for example for comparison across herds or for evaluation of feed management for dry cows and transition cows. Because the prediction error variance of the mean of a group of samples is $\sqrt{n}$ times smaller than the prediction error variance of an individual sample (Heuer et al., 2001), the FTIR predictions of Ac and BHBA are accurate enough for usage as a herd parameter.

Further research on this topic is underway to evaluate the additional value of FTIR predictions of Ac and BHBA for detection of subclinical ketosis, compared with detection based on the other milk constituents only. Furthermore, the relationship between FTIR predictions of milk Ac or BHBA and blood parameters related to subclinical ketosis will be investigated.

\section{CONCLUSIONS}

The Ac and BHBA in milk were predicted using FTIR spectrometry. The correlation with chemical method results was around 0.80 . Using thresholds of $0.15 \mathrm{mM}$ for Ac and $0.10 \mathrm{~m} M$ for BHBA, high values for Ac or BHBA were detected with a sensitivity of 69 to $70 \%$, a specificity of $95 \%$, with 25 to $27 \%$ false positives and 6 to $7 \%$ false negatives. These results show that FTIR predictions for Ac and BHBA are valuable for screening cows for subclinical ketosis and for evaluation of the herd management with respect to subclinical ketosis.

\section{REFERENCES}

Carrier, J., S. Stewart, S. Godden, J. Fetrow, and P. Rapnicky. 2004. Evaluation and use of three cowside tests for detection of subclinical ketosis in early postpartum cows. J. Dairy Sci. 87:3725-3735.

Correa, M. T., H. Erb, and J. Scarlett. 1993. Path analysis for seven postpartum disorders of Holstein cows. J. Dairy Sci. 76:13051312
Dohoo, I. R., and S. W. Martin. 1984. Subclinical ketosis: Prevalence and associations with production and disease. Can. J. Comp. Med. 48:1-5.

Duffield, T. F., D. Sandals, K. E. Leslie, K. Lissemore, B. W. McBride, J. H. Lumsden, P. Dick, and R. Bagg. 1998. Efficacy of Monensin for the prevention of subclinical ketosis in lactating dairy cows. J. Dairy Sci. 81:2866-2873.

Duffield, T. 2003. Minimizing subclinical metabolic diseases. Pages 1-14 in Proc. Tri-State Dairy Nutr. Conf., Fort Wayne, IN.

Enjalbert, F., M. C. Nicot, C. Bayourthe, and R. Moncoulon. 2001. Ketone bodies in milk and blood of dairy cows: Relationship between concentrations and utilization for detection of subclinical ketosis. J. Dairy Sci. 84:583-589.

Geishauser, T., K. Leslie, D. Kelton, and T. Duffield. 1998. Evaluation of five cowside tests for use with milk to detect subclinical ketosis in dairy cows. J. Dairy Sci. 81:438-443.

Geishauser, T., K. Leslie, J. Tenhag, and A. Bashiri. 2000. Evaluation of eight cow-side ketone tests in milk for detection of subclinical ketosis in dairy cows. J. Dairy Sci. 83:296-299.

Hansen, P. W. 1999. Screening of dairy cows for ketosis by use of infrared spectroscopy and multivariate calibration. J. Dairy Sci. 82:2005-2010.

Heuer, C., H. J. Luinge, E. T. G. Lutz, Y. H. Schukken, J. H. van der Maas, H. Wilmink, and J. P. T. M. Noordhuizen. 2001. Determination of acetone in cow milk by Fourier transform infrared spectroscopy for the detection of subclinical ketosis. J. Dairy Sci. 84:575-582.

International Organization for Standardization (ISO). 1999. ISO 1211|IDF 1: Milk-Determination of fat content-Gravimetric method (Reference method). ISO, Geneva, Switzerland.

International Organization for Standardization (ISO). 2001. ISO 8968-1|IDF 20-1: Milk-Determination of nitrogen content-Part 1: Kjeldahl method. ISO, Geneva, Switzerland.

International Organization for Standardization (ISO). 2004. ISO 14637|IDF 195: Milk-Determination of urea content-Enzymatic method using difference in $\mathrm{pH}$ (Reference method). ISO, Geneva, Switzerland.

Larsen, T., and N. I. Nielsen. 2005. Fluorometric determination of $\beta$-hydroxybutyrate in milk and blood plasma. J. Dairy Sci. 88:2004-2009.

Lyons, D. T., A. E. Freeman, and A. L. Kuck. 1991. Genetics of health traits in Holstein cattle. J. Dairy Sci. 74:1092-1100.

Miettinen, P. V. A. 1994. Relationship between milk acetone and milk yield in individual cows. J. Vet. Med. Ser. A 38:427-432.

Reksen, O., Ø. Havrevoll, Y. T. Gröhn, T. Bolstad, A. Waldmann, and E. Ropstad. 2002. Relationships among body condition score, milk constituents, and postpartum luteal function in Norwegian dairy cows. J. Dairy Sci. 85:1406-1415.

Reist, M., D. Erdin, D. von Euw, K. Tschuemperlin, H. Leuenberger, Y. Chilliard, H. M. Hammon, C. Morel, C. Philipona, Y. Zbinden, N. Kuenzi, and J. W. Blum. 2002. Estimation of energy balance at the individual and herd level using blood and milk traits in high-yielding dairy cows. J. Dairy Sci. 85:3314-3327.

Reist, M., D. Erdin, D. von Euw, K. Tschuemperlin, H. Leuenberger, C. Delavaud, Y. Chilliard, H. M. Hammon, N. Kuenzi, and J. W. Blum. 2003. Concentrate feeding strategy in lactating dairy cows: Metabolic and endocrine changes with emphasis on leptin. J. Dairy Sci. 86:1690-1706.

Uribe, H. A., B. W. Kennedy, S. W. Martin, and D. F. Kelton. 1995. Genetic parameters for common health disorders of Holstein cows. J. Dairy Sci. 78:421-430. 